\title{
Temporal transferability of models of mode-destination choice for the Greater Toronto and Hamilton Area
}

\author{
James Fox ${ }^{a}$ \\ University of Leeds
}

\author{
Andrew Daly ${ }^{\mathrm{b}}$ \\ University of Leeds
}

\author{
Stephane Hess ${ }^{c}$ \\ University of Leeds
}

\author{
Eric Miller ${ }^{d}$ \\ University of Toronto
}

\begin{abstract}
Transport planning relies extensively on forecasts of traveler behavior over horizons of 20 years and more. Implicit in such forecasts is the assumption that travelers' tastes, as represented by the behavioral model parameters, are constant over time. In technical terms, this assumption is referred to as the "temporal transferability" of the models. This paper summarizes the findings from a literature review that demonstrates there is little evidence about the transferability of mode-destination models over typical forecasting horizons. The literature review shows a relative lack of empirical studies given the importance of the issue. To provide further insights and evidence, models of commuter mode-destination choice been developed from household interview data collected across the Greater Toronto and Hamilton Area in 1986, 1996, 2001, and 2006. The analysis demonstrates that improving model specification improves the transferability of the models, and in general the transferability declines as the transfer period increases. The transferability of the level-of-service parameters is higher than transferability of the cost parameters, which has important implications when considering the accuracy of forecasts for different types of policy. The transferred models over-predict the key change in mode share over the transfer period-specifically, the shift from local transit to auto driver between 1986 and 1996-but under-predict the growth in commuting tour lengths over the same period.
\end{abstract}

\section{$1 \quad$ Introduction}

Transport planning relies extensively on forecasts of traveler behavior over horizons of 20 years and more. Implicit in such forecasts is the assumption that travelers' tastes, as represented by the behavioral model parameters, are constant over time. In technical terms, this assumption is referred to as the "temporal transferability" of the models used to represent travel behavior. This research seeks to investigate the existing evidence base underlying the assumption of temporal transferability, undertake additional empirical analysis to add to the evidence base, and set out recommendations for practitioners to improve the way they make forecasts of traveler behavior.

Section 2 discusses the motivation for the work in more detail, highlighting why the issue of temporal transferability is an important consideration when applying models to make forecasts of behavior.

Section 3 explores the issue of model transferability. It starts with a discussion of what we mean by model transferability, and draws an important distinction between temporal and spatial transferability. Measures that can be used to assess model transferability are set out, with a discussion of their relative strengths and weaknesses. This section also summarizes the findings from a recent literature review to investigate what evidence exists about the temporal transferability of models of mode and destination choice.

Section 4 summarizes the data used to undertake the transferability analysis. The main dataset is the Transportation Tomorrow Survey (TTS) data, which provides large samples of home-work trips records collected in 1986, 1996, 2001, and 2006 across the Greater Toronto and Hamilton (GTHA) area. This data is supported by highway and transit level-of-service data generated using the Emme

\footnotetext{
${ }^{a}$ tsjbf@leeds.ac.uk

bdaly@rand.org

cS.Hess@its.leeds.ac.uk

d miller@ecf.utoronto.ca
}

Copyright 2014 James Fox, Andrew Daly, Stephane Hess, and Eric Miller.

Licensed under the Creative Commons Attribution - NonCommercial License 3.0. 
software ${ }^{1}$ as well as employment attraction data taken from census data.

Section 5 presents findings from the empirical analysis of the temporal transferability of homework models for the GTHA area. The results from both statistical and predictive tests of transferability are presented.

The paper concludes in Section 6 with a summary of findings from the empirical analysis, then sets out the plans for the remainder of the research.

\section{Motivation}

The importance to transport practice of models able to generate accurate forecasts of travel behavior should not be underestimated. Strategic forecasting models are used by local and national government agencies to forecast demand for existing and planned transport infrastructure and to test the effectiveness of different policy options. The complexity of this process is further increased by the need to take account of demographic changes as well as changes in the transport infrastructure.

To make these forecasts, the approach often followed is to develop cross-sectional models that represent a tractable simplification of current behavior, and then use those models to forecast behavior. The forecasting problem is further simplified by separating the key travel choice decisions on a given day, typically:

- travel frequency - whether to travel, and if so, how many times

- mode of travel

- destination zone

- time of day

For each of these choices, separate models are usually developed by travel purpose, as experience has demonstrated that the factors influencing these choices vary according to travel purpose. The focus of this research is on the mode and destination choice decisions, and more specifically, on disaggregate models of simultaneous mode and destination choice.

In a forecasting context, mode-destination models are used to assess the effectiveness of different policies over forecasting horizons of 20 years and beyond. These models can include detailed socioeconomic segmentation, enabling both a better fit to the estimation dataset and an ability to predict the impact of trends in the input variables over time, such as increasing car ownership or aging of the population. By making forecasts of how the population shifts between socioeconomic segments over time, the impact of trends such as aging of the population on demand for travel can be assessed.

However, forecasting travel demands in this way relies on a significant assumption, namely, that the parameters that describe behavior in the base year can be used to predict future behavior, an issue that is referred to as transferability, but over recent years this issue has dropped off the radar. An important issue for further research is that the model that best explains current behavior may not necessarily be the best tool for forecasting due to the potential for overfitting.

If the assumption of transferability is strongly violated, then the forecasts will be subject to error, irrespective of how well the models fit in the base year, how much segmentation they incorporate, and how accurately future model inputs can be forecast. As is clear from the literature review referenced in this paper, the topic of transferability has received less and less attention in recent years, and evidence specific to mode-destination models would be useful for investigating the assumption of model transferability over typical forecasting horizons.

1 http://www.inro.ca/en/products/emme/, accessed 17/10/13. 


\section{Transferability}

\subsection{Defining transferability}

Koppelman and Wilmot (1982) provide the following definition of transferability, which seems to be the best definition provided in the literature: "First, we define transfer as the application of a model, information, or theory about behavior developed in one context to describe the corresponding behavior in another context. We further define transferability as the usefulness of the transferred model, information or theory in the new context."

The first part of this definition can be interpreted quite broadly. For example, applying a model based on principles of utility maximization assumes that those principles apply in the context in which the model is applied as well as in the context in which the model is developed. However, the focus of the transferability literature, and of this paper, is on model transferability - that is to say, assessing the ability of models developed in one context to explain behavior in another context, under the assumption that the underlying behavioral theory on which the model is based is equally applicable in the two contexts.

\subsection{Temporal and spatial transferability}

A key distinction is made in the literature between temporal transferability and spatial transferability. Temporal transferability is concerned with the application of models developed using data collected at one point in time at another point in time, whereas spatial transferability is concerned with the application of models developed using data from one spatial area in another spatial area, and it is not uncommon for models to be transferred over both space and time.

Spatial transfers typically involve a transfer sample - a sample of choices observed in the transfer context - which may allow a locally estimated model to be developed for comparison with the model transfer. When a model is applied to forecast behavior, this is a transfer of the model to a new temporal context. However, unlike many spatial transfers, no temporal transfer sample is available. There is, therefore, an important practical difference between temporal and spatial transfers.

Temporal transferability can be assessed, however, by using two datasets collected at different points in time from the same spatial area. Models estimated from the two samples can be compared to make assessments of model transferability, and from these, conclusions can be drawn about the temporal transferability of similar models used for forecasting. This is the approach used in the transferability analysis presented in Section 5 .

\subsection{Assessing transferability}

As noted above, in a forecasting context testing for transferability is not possible in advance; we are producing forecasts for a future period and by definition the accuracy of these forecasts can only be assessed in the future. However, evidence on the temporal transferability of particular types of models can be produced by looking at historical studies where we can compare the forecasts to what actually occurred in reality. Specifically, temporal transferability can be assessed by using datasets that have been collected at two points in time in the same geographical area. Provided identical, or similar, variables are collected in the two cases, it is possible to use the sets of data to develop identically specified models at both points in time and make assessments of model transferability. This approach makes the assumption that the actual model type is transferable, and that transferability is only influenced by the specification of the utility function. 
The measures of transferability used in the literature can be placed into two broad categories. First are statistical tests of the hypothesis of parameter transferability, which were the key measures of transferability employed in the early literature. Many of these tests rely on the availability of a transfer sample, which is used to develop a locally estimated model; the transferred model is then assessed relative to this locally estimated model.

The second category is predictive measures, which are assessments of the predictive ability of a model in the transfer context. Predictive measures can be used to make assessments of model transferability, but they do not necessarily directly measure transferability and so need to be interpreted with caution.

\section{Statistical tests}

A frequently used statistical test in the literature is the Transferability Test Statistic (TTS), which assesses the transferability of the base model parameters $b$ in the transfer context $t$, under the hypothesis that the two sets of parameters are equal:

$$
\operatorname{TTS}_{t}\left(\beta_{b}\right)=-2\left(L L_{t}\left(\beta_{b}\right)-L L_{t}\left(\beta_{t}\right)\right)
$$

where $L L_{t}\left(\beta_{b}\right)$ is the log-likelihood for the base model applied to the transfer data, $L L_{t}(\beta)$ is the $\log$-likelihood for the model estimated on the transfer data, and TTS is $\beta^{2}$ distributed with degrees of freedom equal to the number of model parameters. It can be seen that this test is the same as the standard likelihood ratio test but applied to pairs of log-likelihood values in a different context. An early example of the application of the test in the context of model transferability is a mode choice transfer study by Atherton and Ben-Akiva (1976), though the TTS terminology seems to have been coined by Koppelman and Wilmot (1982).

The TTS gives a strict pass/fail test for transferability and would be expected to show a failure of transferability if sufficient data are available.

The Transfer Index (TI) was devised by Koppelman and Wilmot (1982) and measures the predictive accuracy of the transferred model relative to a locally estimated model, with an upper bound of one. A reference model is used in the calculation of TI, typically a market shares model in the case of mode choice.

$$
T_{t}\left(\beta_{b}\right)=\frac{\left(L_{t}\left(\beta_{b}\right) \geq L_{t}\left(\beta_{t}^{\text {ref }}\right)\right.}{\left(L_{t}\left(\beta_{t}\right) \geq L_{t}\left(\beta_{t}^{\text {ref }}\right)\right.}
$$

where: $\beta_{\mathrm{t}}^{\text {ref }}$ is a reference model, usually quite simple, for the transfer data; and

$$
L L_{t}\left(\beta_{t}\right) \geq L L_{t}\left(\beta_{b}\right) \geq L L_{t}\left(\beta_{r e f}^{t}\right)
$$

Unlike the TTS, the TI neither accepts nor rejects the hypothesis of model transferability and is therefore not a statistical test in the strict sense. Rather, it provides a relative measure of model transferability. Within a given study area, the TI can be used to directly assess different sets of models. When comparing between different studies, the TI still provides insight if the same reference model specification is used, but it does not have a general scale in a formal sense; it is not directly a function of the amount of data available. The TI is the key statistical test of transferability that has been employed in the transferability analysis presented in Section 4. 
The statistical measures discussed above are concerned with the overall fit to the data, and are the measures that have been used in the literature to assess transferability. It is also possible to analyze differences in individual parameter values, using information on the significance of the parameter in the base and transfer models. For example, the cost and time parameters in a model are key to determining the responsiveness of a model to different policy tests, and so changes in these parameters over time are of particular relevance. Changes in individual parameter value can be calculated using the relative error measure (REM):

$$
\frac{R E M=\left(\beta_{t}-\beta_{b}\right)}{\beta_{b}}
$$

\section{Predictive measures}

Following an initial focus on statistical measures, predictive measures were increasingly used to assess transferability as the transferability literature developed. For example, Lerman (1981) argued that the early transferability literature had used an over-restrictive definition of transferability, with an overemphasis on statistical tests, and argued that transferability should not be seen as a binary issue, but rather, that the extent of transferability should be explored. In the same book, Ben-Akiva (1981) argued that achieving perfect transferability is impossible, as a model is never perfectly specified, and therefore pragmatic transferability criteria are required in addition to standard statistical tests.

Predictive measures, however, need to be interpreted carefully when making assessments of model transferability. In cases where both base and transfer samples are available, and provided both datasets give accurate samples of individual choices, the ability of the base model to predict choices in the transfer context is a direct test of the transferability of the model.

\subsection{Review of temporal transferability literature}

In Fox and Hess (2010), we presented a review of the existing evidence regarding the temporal transferability of mode-destination choice models over forecasting horizons of 20 years and beyond. Here we summarize the key findings from that review.

Six studies were reviewed that made statistical tests of transferability, summarized in Table 1 . These studies support the hypothesis that mode choice models can be transferred over time, with four of the six studies concluding that the models tested were transferable. In addition, an additional four studies were identified that have assessed temporal transferability of mode choice models using predictive tests. These studies are summarized in Table 2. Some of the validation studies demonstrate that the models are able to predict the impact on mode share of substantial changes in level-of-service over short periods.

A feature of the evidence base is that much of it is based on short-term forecasts of up to 10 years. However, many transport models are applied over forecast periods of 20 years or more, and it seems reasonable to hypothesize that over longer time intervals, transferability would be less likely to be accepted. That said, the single body of evidence on longer-term transferability - the studies from Toronto that developed mode choice models and distribution models - is supportive of model transferability (Badoe and Miller, 1995, and Elmi, Badoe and Miller 1997).

An empirical finding from the mode choice studies is that improving model specification improves model transferability. Although the improvements in model specification described are often the addition of socioeconomic parameters, this improvement in model performance seems to come about because the improved models provide better estimates of the key cost and time parameters that respond to short-term policy changes. Over a longer-term forecasting horizon, substantial changes in the distribution of the population across segments would be expected, and so the findings in terms of model 
specification may be different, depending on the relative stability of level-of-service and socioeconomic parameters over the longer term.

Only two studies of temporal transferability have considered simultaneous models of mode and destination choice (the focus of this particular paper); most of the literature is from mode choice models. Gunn's study found a good level of temporal transferability, but in the Karasmaa and Pursula work, three out of four level-of-service parameters were not transferable. In general, the transferability for destination choice may be quite different to the transferability of mode choice. This has important implications when jointly modeling both choices.

The dates of the studies are noteworthy, with more than half published in the 1970s and 1980s, and with no papers published over the last decade. Clearly research efforts into the issue of model transferability have been limited since the cluster of work in the 1970s and early 1980s. Additionally, the evidence that models of mode-destination choice are temporally transferable over forecasting intervals of 20-plus years is extremely limited. Given the importance of such long-term forecasts in transport planning, this is a serious shortcoming in the field and an important area for future research.

Table 1: Temporal mode and mode-destination choice transferability studies, statistical tests of transferability.

\begin{tabular}{|c|c|c|c|c|c|}
\hline Paper & Area & Purpose(s) & Time Frame & Degree of Transferability & Comments \\
\hline Train (1978) & $\begin{array}{l}\text { San Francisco, } \\
\text { U.S. }\end{array}$ & Commute & & $\begin{array}{l}\text { LOS parameters more } \\
\text { stable than other terms }\end{array}$ & Mode choice models \\
\hline Silman (1981) & Tel-Aviv, Israel & Commute & 4 years (1972-1976) & $\begin{array}{l}\text { Good: time parameters } \\
\text { particularly stable }\end{array}$ & Mode choice models \\
\hline McCarthy (1982) & $\begin{array}{l}\text { San Francisco, } \\
\text { U.S. }\end{array}$ & Commute & $\begin{array}{l}1.5 \text { years } \\
(1973 / 74-1975)\end{array}$ & $\begin{array}{l}\text { Parameters stable over } \\
\text { short-term }\end{array}$ & $\begin{array}{l}\text { Mode choice models Box- } \\
\text { Cox transforms used }\end{array}$ \\
\hline $\begin{array}{l}\text { Badoe and Miller } \\
(1995,1998)\end{array}$ & $\begin{array}{l}\text { Toronto, } \\
\text { Canada }\end{array}$ & Commuter & $\begin{array}{l}22 \text { years } \\
(1964-1986)\end{array}$ & $\begin{array}{l}\text { Statistical differences } \\
\text { between parameters, } \\
\text { but models but broadly } \\
\text { transferable in terms of } \\
\text { predictive performance, } \\
\text { ASCs and scale change } \\
\text { over time }\end{array}$ & \\
\hline $\begin{array}{l}\text { Karasmaa and } \\
\text { Pursula (1997) }\end{array}$ & $\begin{array}{l}\text { Helsinki, } \\
\text { Finland }\end{array}$ & Commute & $\begin{array}{l}7 \text { years } \\
(1981-1988)\end{array}$ & $\begin{array}{l}\text { Poor: } 3 \text { out of } 4 \text { LOS } \\
\text { parameters } \\
\text { not stable }\end{array}$ & Mode-destination models \\
\hline Gunn (2001) & Netherlands & $\begin{array}{l}\text { Commute, personal } \\
\text { business, shopping, } \\
\text { social and recre- } \\
\text { ational }\end{array}$ & $\begin{array}{l}13 \text { years } \\
(1982-1995)\end{array}$ & $\begin{array}{l}\text { Good, particularly for } \\
\text { level-of-service param- } \\
\text { eters }\end{array}$ & $\begin{array}{l}\text { Mode-destination models, } \\
\text { some evidence that trans- } \\
\text { ferability may vary with } \\
\text { purpose }\end{array}$ \\
\hline
\end{tabular}


Table 2: Temporal mode choice studies, predictive tests of transferability.

\begin{tabular}{|l|l|l|l|l|l|}
\hline Paper & Area & Purpose(s) & Time Frame & Predictive Performance & Comments \\
\hline Parody (1977) & $\begin{array}{l}\text { Univ. of Amherst, } \\
\text { Mass., U.S. }\end{array}$ & Commute & $\begin{array}{l}\text { 4 waves: } \\
\text { 1. Autumn 72 } \\
\text { 2. Spring 73 } \\
\text { 3. Autumn 73 } \\
\text { 4. Spring 74 }\end{array}$ & $\begin{array}{l}\text { Good, substantial } \\
\text { improvement when } \\
\text { model specification } \\
\text { improved with socio- } \\
\text { economic terms }\end{array}$ & $\begin{array}{l}\text { Mode choice models, } \\
\text { large changes in } \\
\text { modal costs over } \\
\text { time period }\end{array}$ \\
\hline $\begin{array}{l}\text { Ben-Akiva and } \\
\text { Atherton (1977) }\end{array}$ & $\begin{array}{l}\text { Washington D.C., U.S., } \\
\text { Santa Monica } \\
\text { U.S. (application only) }\end{array}$ & Commute & $\begin{array}{l}\text { D.C. 1970-74 } \\
\text { S.M. 1974 }\end{array}$ & $\begin{array}{l}\text { Good in response to } \\
\text { significant changes in } \\
\text { LOS }\end{array}$ & $\begin{array}{l}\text { Mode choice models, } \\
\text { focus on car-pooling } \\
\text { policies }\end{array}$ \\
\hline Train (1978, 1979) & San Francisco, U.S. & Commute & $\begin{array}{l}\text { Poor for transit due to } \\
\text { problems with input } \\
\text { data; predictions im- } \\
\text { prove with improved } \\
\text { model specification }\end{array}$ & $\begin{array}{l}\text { Mode choice models, } \\
\text { lack of info. for new } \\
\text { BART mode, errone- } \\
\text { ous walk time data }\end{array}$ \\
\hline Silman (1981) & Tel-Aviv, Israel & Commute & $\begin{array}{l}4 \text { years } \\
\text { (1972-1976) }\end{array}$ & $\begin{array}{l}\text { Mixed: main car driver } \\
\text { and bus modes } \\
\text { predicted well, minor } \\
\text { car passenger mode } \\
\text { significantly overpre- } \\
\text { dicted }\end{array}$ & Mode choice models \\
\end{tabular}

\section{$4 \quad$ Data}

\subsection{Transportation Tomorrow Survey}

The Transportation Tomorrow Survey (TTS) data is a comprehensive travel survey conducted every five years across the Greater Toronto and Hamilton Area (GTHA) ${ }^{2}$. The first TTS was conducted in 1986 and obtained completed interviews for a 4.2\% random sample of all households in the GTHA. The 1991 survey was a smaller update of the 1986 survey, focusing primarily on those regions that had experienced high growth since 1986, with only $0.5 \%$ of households sampled in low-growth regions. Full surveys were conducted again in 1996, 2001, and 2006. Given the much lower sample rate in the 1991 survey, it was decided to drop the 1991 data from the transferability analysis.

The geographical area surveyed has grown over time, so that by 2006 as well as the GTHA (the extent of the original 1986 survey) the area surveyed included a one-municipality ring around the GTHA, the Niagara and Waterloo municipalities, the counties of Dufferin, Peterborough, Simcoe, Victoria, and Wellington, and the cities of Barrie, Brantford, Guelph, Peterborough, and Orangeville. However, to provide a consistent spatial definition for the transferability analysis, only data from the GTHA data has been included in the analysis.

Table 3 summarizes the key features of the GTHATTS samples used for the transferability analysis. 
Table 3: GTHA TTS samples.

\begin{tabular}{|c|c|c|c|c|}
\hline & 1986 & 1996 & 2001 & 2006 \\
\hline TTS households & 61,453 & 88,898 & 113,608 & 112,486 \\
\hline TTS persons & 171,086 & 243,286 & 315,202 & 305,696 \\
\hline Expanded households & $1,466,080$ & $1,805,021$ & $1,975,155$ & $2,160,059$ \\
\hline Expanded persons & $4,062,642$ & $4,926,367$ & $5,386,137$ & $5,871,885$ \\
\hline \% Households sampled & $4.2 \%$ & $4.9 \%$ & $5.8 \%$ & $5.2 \%$ \\
\hline$\%$ Persons sampled & $4.2 \%$ & $4.9 \%$ & $5.9 \%$ & $5.2 \%$ \\
\hline Home-work trips & 52,160 & 63,869 & 79,371 & 74,993 \\
\hline
\end{tabular}

The population of the GTHA grew significantly between 1986 and 2006, with a 47 percent increase in the number of households and a 45 percent increase in the number of persons. It can be seen that the TTS data provides substantial samples of home-work trips for analysis, making it an ideal dataset for making tests of model transferability over transfer periods of up to 20 years. The transferability analysis used home-work trips because the samples of home-work trips in each year of the TTS had already been extracted for previous model development work, and supporting peak-period level-of-service matrices existed to model these home-work trips.

\subsection{Level-of-service and attraction data}

In order to develop models of simultaneous mode-destination choice, level-of-service (LOS) matrices, which provide skimmed travel times for highway and transit modes, were required. Because the models represent destination choice, this information is required for both the chosen and not chosen destination alternatives, and therefore matrices defining LOS for each possible combination of origin and destination were required.

Fortunately, the TTS data has already been used to develop transport models for the GTHA region, and this meant that highway and transit networks had been coded using the Emme software for each of the four years of TTS data used for the transferability analysis (1986, 1996, 2001, and 2006). As the transferability analysis has been undertaken for home-work travel, the LOS supplied is for peak hour assignments to AM-peak networks.

The level of detail represented in the zoning systems has increased over time. The zone system used for the 1986 LOS included 1404 zones. The zone system used for the 1996 LOS incorporated substantial revisions to the traffic zones for the city of Toronto, York region, and Durham region, resulting in a 19.4\% increase in the number of zones to 1677. The 2001 and 2006 zone systems incorporate further increases in the number of zones, to 1717 and 1845, respectively. The increase in the number of zones between 2001 and 2006 resulted from increases in detail in one particular corridor, and therefore outside of this corridor the 1996, 2001, and 2006 zone systems contain similar levels of detail, whereas the 1986 zone system is more aggregate.

The use of a more detailed zoning system should result in more accurate LOS data, particularly when considering access to local transit and distances for the walk mode. Therefore, ceteris paribus, we would expect more accurate LOS measures for the 1996, 2001, and 2006 datasets relative to 1986.

Zonal parking cost information was supplied for downtown zones, which was added to the perkilometer costs for auto travel. It was assumed that half of all workers have to pay for parking, and that the other half of workers have their parking places provided for free by their employer. This is the standard assumption used to develop transport demand models for the GTHA region and was confirmed 
by analysis of the 1996 TTS data, which demonstrated that for the sample of home-work trips to zones with non-zero parking costs, $49.6 \%$ of individuals paid for parking. The pay for parking information was not collected in the 1986 data. It was collected in 2001 and 2006 but was not available for this analysis and thus the 1996 figure, which is consistent with the standard modeling assumption for the GTHA region, has been used for all four years of data.

For transit, fare matrices were used to define costs. Attraction data by zone was assembled from census data, which is collected every five years in Toronto (the TTS data was collected in census years). Total employment has been used as the attraction variable.

\section{$5 \quad$ Transferability analysis}

\subsection{Model tests}

A number of papers in the mode choice transferability literature have demonstrated that improving model specification improves model transferability (see in particular Badoe and Miller (1995), who investigated mode choice models estimated from 1964 and 1986 Toronto datasets). To investigate whether this finding holds for mode-destination models, transferability tests were undertaken for three different model specifications. In specification A, mode and destination choices are explained by cost parameters, level-of-service terms, and destination and mode constants. In specification B, car availability terms are added, which are expected to significantly improve the performance of the mode choice model. In specification C, further socioeconomic terms to explain mode choice are added ${ }^{3}$. The model specifications were developed on the basis of tests undertaken using the base 1986 data. To investigate changes in cost sensitivity over time, tests were also undertaken starting from specification $\mathrm{B}^{4}$, but with $\log$ cost only (specification D) and with linear cost only (specification E).

Table 4 summarizes the five model specifications tested. "IVT" denotes in-vehicle time. The four modes represented in the model are auto driver (AD), auto passenger (AP), local transit (LT), and walk (WK).

3 The age information available in the 2001 data did not allow specification $\mathrm{C}$ to be estimated.

4 Specification B was used rather than specification C so that models could be estimated for the 2001 data. 
Table 4: Model specifications

\begin{tabular}{|c|c|c|c|c|c|c|c|c|}
\hline \multirow{2}{*}{ Utility function term } & \multirow{2}{*}{$\begin{array}{l}\text { Parameter } \\
\text { name }\end{array}$} & \multirow{2}{*}{ Modes } & \multirow{2}{*}{ Definition } & \multicolumn{5}{|c|}{ Specification } \\
\hline & & & & A & B & $\mathrm{C}$ & $\mathrm{D}$ & $\mathrm{E}$ \\
\hline Cost terms & & & & & & & & \\
\hline Log cost & LogCost & $\mathrm{AD}, \mathrm{LT}$ & Cost (cents) & $\sqrt{ }$ & $\sqrt{ }$ & $\sqrt{ }$ & $\sqrt{ }$ & \\
\hline Cost & Cost & $\mathrm{AD}, \mathrm{LT}$ & Log of cost (cents) & $\sqrt{ }$ & $\sqrt{ }$ & $\sqrt{ }$ & & $\sqrt{ }$ \\
\hline Level-of-service terms & & & & & & & & \\
\hline Auto time & AutoTime & $\mathrm{AD}, \mathrm{AP}$ & Auto in-vehicle time (mins) & $\sqrt{ }$ & $\sqrt{ }$ & $\sqrt{ }$ & $\sqrt{ }$ & $\sqrt{ }$ \\
\hline Transit IVT & TranIVT & LT & Transit in-vehicle time (mins) & $\sqrt{ }$ & $\sqrt{ }$ & $\sqrt{ }$ & $\sqrt{ }$ & $\sqrt{ }$ \\
\hline Transit wait time & TranWait & LT & Transit wait time (mins) & $\sqrt{ }$ & $\sqrt{ }$ & $\sqrt{ }$ & $\sqrt{ }$ & $\sqrt{ }$ \\
\hline Transit walk time & TranWalk & LT & Transit walk time (mins) & $\sqrt{ }$ & $\sqrt{ }$ & $\sqrt{ }$ & $\sqrt{ }$ & $\sqrt{ }$ \\
\hline Auto passenger distance & APDist & AP & Distance (km) & $\sqrt{ }$ & $\sqrt{ }$ & $\sqrt{ }$ & $\sqrt{ }$ & $\sqrt{ }$ \\
\hline Walk distance & WalkDist & WK & Distance $(\mathrm{km})$ & $\sqrt{ }$ & $\sqrt{ }$ & $\sqrt{ }$ & $\sqrt{ }$ & $\sqrt{ }$ \\
\hline Destination terms ${ }^{1}$ & & & & & & & & \\
\hline CBD destination & CBDDest & all & CBD destination constant & $\sqrt{ }$ & $\sqrt{ }$ & $\sqrt{ }$ & $\sqrt{ }$ & $\sqrt{ }$ \\
\hline CBD destination LT & CBDLT & LT & CBD destination constant & $\sqrt{ }$ & $\sqrt{ }$ & $\sqrt{ }$ & $\sqrt{ }$ & $\sqrt{ }$ \\
\hline Mode constants & & & & & & & & \\
\hline Auto passenger & $\mathrm{AP}$ & $\mathrm{AP}$ & $\mathrm{AP}$ constant ( $\mathrm{AD}$ is base) & $\sqrt{ }$ & $\sqrt{ }$ & $\sqrt{ }$ & $\sqrt{ }$ & $\sqrt{ }$ \\
\hline Local transit & LT & LT & AP constant (LT is base) & $\sqrt{ }$ & $\sqrt{ }$ & $\sqrt{ }$ & $\sqrt{ }$ & $\sqrt{ }$ \\
\hline Walk & WK & WK & AP constant (WK is base) & $\sqrt{ }$ & $\sqrt{ }$ & $\sqrt{ }$ & $\sqrt{ }$ & $\sqrt{ }$ \\
\hline Car availability terms & & & & & & & & \\
\hline $\mathrm{AD}, 2+$ autos & AD2pVeh & $\mathrm{AD}$ & $2+$ autos in household & & $\sqrt{ }$ & $\sqrt{ }$ & $\sqrt{ }$ & $\sqrt{ }$ \\
\hline AP, 1 auto & AP1Veh & AP & 1 auto in household & & $\sqrt{ }$ & $\sqrt{ }$ & $\sqrt{ }$ & $\sqrt{ }$ \\
\hline $\mathrm{AP}, 2+$ autos & AP2pVeh & $\mathrm{AP}$ & $2+$ autos in household & & $\sqrt{ }$ & $\sqrt{ }$ & $\sqrt{ }$ & $\sqrt{ }$ \\
\hline Socioeconomic terms & & & & & & & & \\
\hline AD, aged $16-17$ & ADAge1617 & $\mathrm{AD}$ & Constant for $16-17$ year olds & & & $\sqrt{ }$ & & \\
\hline AD, aged $18-25$ & ADAge1825 & $\mathrm{AD}$ & Constant for $18-25$ year olds & & & $\sqrt{ }$ & & \\
\hline $\mathrm{AD}$, aged $26-30$ & ADAge 2630 & $\mathrm{AD}$ & Constant for 26-30 year olds & & & $\sqrt{ }$ & & \\
\hline Walk male & WkMale & WK & Male walk constant & & & $\sqrt{ }$ & & \\
\hline Attraction term & & & & & & & & \\
\hline Total employment & TotEmp & all & Employment at destination & $\sqrt{ }$ & $\sqrt{ }$ & $\sqrt{ }$ & $\sqrt{ }$ & $\sqrt{ }$ \\
\hline Nesting parameter & & & & & & & & \\
\hline Dest.s above modes & TR_D_M & all & $\begin{array}{l}\text { Relative sensitivity of destination and } \\
\text { mode choice }\end{array}$ & $\sqrt{ }$ & $\sqrt{ }$ & $\sqrt{ }$ & $\sqrt{ }$ & $\sqrt{ }$ \\
\hline
\end{tabular}

Both linear and $\log$ cost terms were used, drawing on practical experience that using both linear and $\log$ terms typically gives a better fit to the data than linear-only or log-only forms as well as more plausible destination choice elasticities than log-only formulations (Fox et al.,2009). This specification allows for a degree of non-linearity that is in between linear and log-linear specifications, similar to a Box-Cox transform, but it is easier to estimate.

Structural tests were undertaken using nested logit models to investigate different tree structures for the relative sensitivity of the mode and destination choice decisions. For all years of the TTS data, a model structure with destination choice nested above mode choice gave the best fit to the data. This structure implies there is less error (greater sensitivity) in mode choice than in destination choice for commuting travel in the GTHA. The structure is illustrated in Figure 1: Model structure. ${ }^{5}$.

5 For clarity the mode nest is only illustrated beneath destination 2 but in reality the mode nest appears beneath each destination. 


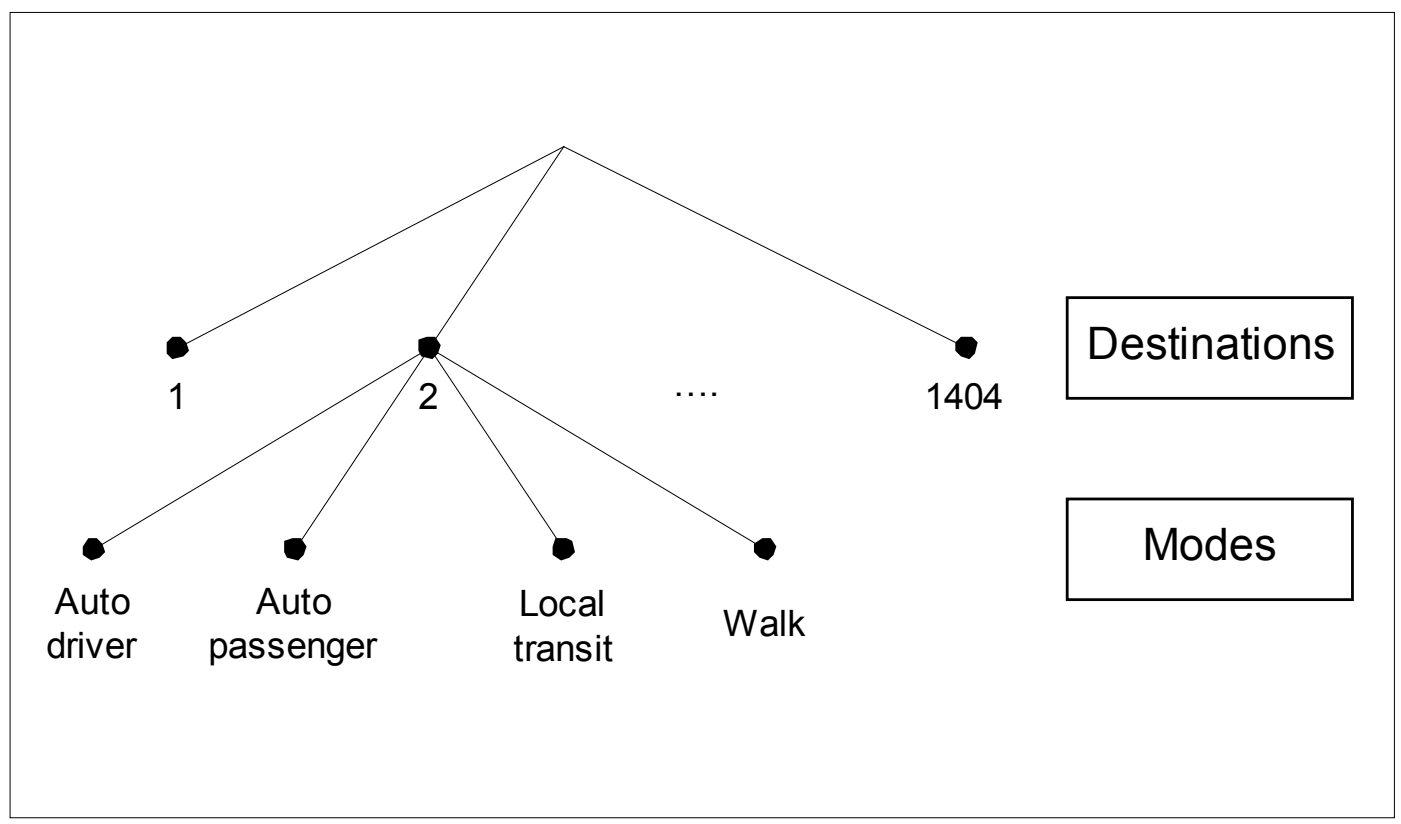

Figure 1: Model structure.

\subsection{Individual parameters}

To compare individual parameters between models estimated separately from each year of the TTS data, it was necessary to take account of scale differences between the different models. To do this, a specification B model was jointly estimated from the 1986, 1996, 2001, and 2006 TTS datasets ${ }^{6}$. All parameters were jointly estimated across all years of data except for the cost parameters, which were estimated separately by year to take account of changes in cost sensitivity over time. The cost parameters were estimated separately by year because, as Appendix A demonstrates, there are significant differences in the values of the cost parameters between the models estimated separately for the different years of TTS data. In the scale model run, the 1986 scale was fixed to one, so all other datasets are scaled relative to the base 1986 data. The resulting scale parameter estimates are given in Table 5 (the t-ratios given are calculated with respect to a value of 1 ).

Table 5: Scale parameters.

\begin{tabular}{|c|c|c|}
\hline Year & Scale & t-ratio \\
\hline 1986 & 1.000 & n/a \\
1996 & 0.883 & 19.6 \\
2001 & 0.850 & 26.2 \\
2006 & 0.929 & 11.4 \\
\hline
\end{tabular}

The results imply that the level of unexplained error is noticeably higher in the 1996, 2001, and 2006 databases, despite the fact that the 1986 zoning system is less detailed than the zoning systems for 1996, 2001, and 2006.

A possible explanation for the pattern of increasing error with time is increased labor market specialization, and the associated decentralization of employment away from central areas, which may make it more difficult to explain commuter destination choice. Statistics Canada (2003) has found that the

6 Ideally, the scale parameter would have been estimated from the most detailed specification C but the 2001 data does not contain the age information required to estimate specification C. 
majority of employment growth over recent decades has taken place in suburban municipalities of urban areas, with a 61 percent increase in employment in these areas between 1981 and 2001 compared to a 7 percent increase in central municipalities over the same period.

Another explanation for the increase in the level of unexplained error over time could be increased income polarization. Hulchanski (2007) highlighted significant increases in income polarization in Toronto between 1970 and 2005. Over that period, the share of middle-income neighborhoods decreased from 66 percent to 29 percent, whereas the share of low-income neighborhoods increased from 19 percent to 53 percent. Furthermore, the location of low-income neighborhoods changed from predominately the inner city to the northeastern and northwestern suburbs. A major drawback of the TTS data is the lack of income data, which means that the models developed cannot take account of variation in cost sensitivity with income. The greater the income polarization the greater the error that will result from assuming the same cost parameters for individuals of all incomes.

Habib et al. (2012) analyzed the mode shares observed in the 1996, 2001, and 2006 TTS datasets for the GTHA. They calculated a measure of modal entropy using the observed mode shares for each model zone. They observed that on average zonal entropy decreased between 1996 and 2006, indicating there are more zones where one mode dominates. It is possible that this tendency for one mode to dominate for a given origin zone could make mode choice harder to explain and thus contribute to the pattern of increasing error with time observed in Table 5.

The scale parameters presented in Table 5 were used to re-scale the parameters from the separately estimated models for 1996, 2001, and 2006 before individual parameters were compared. The large sample sizes mean that most of the parameters in the separately estimated models are precisely estimated, and as a result tests of the significance of the differences in parameter values relative to the 1986 base indicate the parameters to be significantly different in a high proportion of cases, even when the parameters are similar in magnitude. Therefore, the analysis of differences in parameter values has concentrated on differences in parameter magnitude.

The REM measure defined in Equation 3 has been used to calculate the absolute change in individual parameter values relative to the 1986 parameter values. These differences have been calculated separately for the cost terms, the level of service terms, the mode and destination constants, and the socioeconomic terms. For each model analyzed, average REM values have been calculated for each of these four groups. Table 6 summarizes the results obtained. The full results are presented in the Appendix.

Table 6: Average REM measures of change in parameter values by model year and model specification.

\begin{tabular}{|l|ccc|ccc|ccc|}
\cline { 2 - 9 } \multicolumn{1}{c|}{} & \multicolumn{3}{c|}{ Specification A } & \multicolumn{3}{c|}{ Specification B } & \multicolumn{3}{c|}{ Specification C } \\
\multicolumn{1}{c|}{} & 1996 & 2001 & 2006 & 1996 & 2001 & 2006 & 1996 & 2001 & 2006 \\
\hline Cost terms & 0.47 & 1.42 & 0.36 & 0.52 & 1.61 & 0.38 & 0.50 & $\mathrm{n} / \mathrm{a}$ & 0.37 \\
LOS terms & 0.10 & 0.20 & 0.10 & 0.09 & 0.16 & 0.12 & 0.09 & $\mathrm{n} / \mathrm{a}$ & 0.11 \\
Constants & 0.51 & 2.25 & 1.67 & 0.75 & 2.44 & 2.56 & 0.65 & $\mathrm{n} / \mathrm{a}$ & 2.76 \\
Socio-economics & $\mathrm{n} / \mathrm{a}$ & $\mathrm{n} / \mathrm{a}$ & $\mathrm{n} / \mathrm{a}$ & 0.17 & 0.29 & 0.17 & 0.30 & $\mathrm{n} / \mathrm{a}$ & 0.42 \\
\hline
\end{tabular}

Comparing different groups of utility terms, the cost, LOS terms, and socioeconomic terms show much smaller changes in parameter magnitude over time compared to the mode and destination constants. This result is expected, as the constants capture the mean contributions of effects not captured in the other parameters.

The REM measures for the cost terms do not exhibit any consistent pattern of evolution over time, with the largest differences between parameters observed by comparing the 1986 and 2001 parameter values. They do not reduce with improving model specification either, with the largest differences ob- 
served for specification B.

The LOS parameters show the smallest REM measures, i.e., the 1986 parameter values are the most transferable to the other years. The REM measures steadily increase with transfer period, with the highest REM measures calculated for the 20-year transfer to 2006. Comparing across model specifications, the REM measures decrease between specifications $\mathrm{A}$ and $\mathrm{B}$ when the car availability parameters are added. Thus, improving the model specification by adding additional socioeconomic terms improves the transferability of the LOS parameters. However, there is no further improvement in the transferability of the LOS parameters when the age and gender mode terms are added in specification C.

The REM measures for the mode and destination constants show much larger differences in parameter values between years, and indeed some constants have changed sign between years. Thus, the stability of these parameters over time is poor. This result indicates that improving model specification, which will reduce the role of the constants relative to other model terms, would be expected to improve model transferability. This hypothesis is confirmed by the analysis presented in the next section.

The socioeconomic parameters show relatively small changes over time, a result that is reassuring in terms of individual model transferability. Interestingly, the mean REM measure is larger for the specification $\mathrm{C}$ models than for the specification $\mathrm{B}$ models. This is because the car availability parameters, the only socioeconomic parameters present in specification $\mathrm{B}$, are more transferable than the age and gender parameters introduced in specification C. We might expect the mean REM to increase with time from 1986. The 1996 and 2006 model results are consistent with this expectation, but the one 2001 data point is not, with a higher REM measure for specification B in 2001 than in 2006. The same pattern was observed for the cost terms for specifications A and B. Thus, for cost and socioeconomic terms, the 2001 data rather than the 2006 data result in the greatest difference in mean parameter values relative to the 1986 data.

\subsection{Statistical tests of transferability}

The analysis of changes in the cost parameters discussed in Section 5.2 did not reveal any consistent pattern of change in cost sensitivity over time. To determine the best approach for adjusting costs to take account of real-term growth in incomes over time when making model transfers, three different approaches for adjusting costs were tested:

- making no adjustment to costs;

- reducing costs by the growth in GDP/capita over the transfer period; and

- reducing costs by the growth in disposable income over the transfer period.

The GDP/capita measure used was for the province of Ontario rather than the whole of Canada. GDP at the level of the Toronto area was not available.

For three different base years $(1986,1996,2006)$ transfers were made using each of these three approaches, and the fit to the two possible transfer datasets (the two years of data other than the base) was calculated under each of the three possible cost adjustment assumptions. The findings from these tests were:

- for specification B, with log and linear cost terms, adjusting by GDP/capita gave the best fit to the transfer data for three of the six possible transfers, adjusting by disposable income was best for one transfer, and applying no adjustment was best for two transfers;

- for specification $\mathrm{D}$, with a log cost term only, adjusting by GDP/capita gave the best fit for all six possible transfers; and

- for specification E, with a linear cost term only, adjusting by GDP/capita gave the best fit for four of the six possible transfers, and applying no adjustment was best for the other two.

Overall, it was concluded that the best approach for adjusting the cost sensitivity over time was to 
reduce the cost sensitivity by the growth in GDP/capita over time. This approach has been used in all subsequent transferability tests reported.

Four different years of TTS data are available for analysis, and models estimated from a given year can be transferred to the data for the three other years by using the models to make backcasts (i.e., predicting behavior in earlier years) as well as forecasts. Therefore, a total of 12 different transfers can be made - 6 forecasts and 6 backcasts — and any differences in transferability between backcasts and forecasts can be investigated. Transfers have been undertaken for model specifications A, B, and C (except for transfers to/from the 2001 data, where only model specifications A and B can be estimated). The reference models used in the TI calculation are models with constants and tour distance terms by mode only, a specification that ensures that the reference model replicates the observed mode shares and the mean tour lengths by mode in the transfer dataset.

Table 7: Transferability indices, specification A.

\begin{tabular}{|c|cccc|}
\hline Base year & \multicolumn{4}{|c|}{ Transfer year } \\
& 1986 & 1996 & 2001 & 2006 \\
\hline 1986 & $\mathrm{n} / \mathrm{a}$ & 0.522 & 0.617 & 0.456 \\
1996 & 0.636 & $\mathrm{n} / \mathrm{a}$ & 0.659 & 0.550 \\
2001 & 0.478 & 0.402 & $\mathrm{n} / \mathrm{a}$ & 0.610 \\
2006 & 0.667 & 0.617 & 0.724 & $\mathrm{n} / \mathrm{a}$ \\
\hline
\end{tabular}

Table 8: Transferability indices, specification B.

\begin{tabular}{|c|cccc|}
\hline Base year & \multicolumn{4}{|c|}{ Transfer year } \\
& 1986 & 1996 & 2001 & 2006 \\
\hline 1986 & n/a & 0.691 & 0.716 & 0.675 \\
1996 & 0.765 & n/a & 0.777 & 0.672 \\
2001 & 0.594 & 0.606 & n/a & 0.727 \\
2006 & 0.762 & 0.705 & 0.784 & n/a \\
\hline
\end{tabular}

Table 9: Transferability indices, specification C.

\begin{tabular}{|c|cccc|}
\hline Base year & \multicolumn{4}{|c|}{ Transfer year } \\
& 1986 & 1996 & 2001 & 2006 \\
\hline 1986 & $\mathrm{n} / \mathrm{a}$ & 0.733 & $\mathrm{n} / \mathrm{a}$ & 0.781 \\
1996 & 0.796 & $\mathrm{n} / \mathrm{a}$ & $\mathrm{n} / \mathrm{a}$ & 0.713 \\
2001 & $\mathrm{n} / \mathrm{a}$ & $\mathrm{n} / \mathrm{a}$ & $\mathrm{n} / \mathrm{a}$ & $\mathrm{n} / \mathrm{a}$ \\
2006 & 0.764 & 0.743 & $\mathrm{n} / \mathrm{a}$ & $\mathrm{n} / \mathrm{a}$ \\
\hline
\end{tabular}

Examining the transferability index (TI) values for specification A first, the transferred models explain $40-70 \%$ of the behavior explained by the model re-estimated in the transfer context (relative to the reference model). Lower TI values might be expected for longer transfers but no consistent pattern emerges.

Coming on to the TI values for specification $\mathrm{B}$, the TI values are higher than those for specification A for each of the 12 transfers. Therefore improving the model specification with the addition of car availability terms has consistently improved the transferability of the models. There is no evidence that the models are more transferable when used to make forecasts than backcasts or vice-versa.

The TI values for specification $\mathrm{C}$ are consistently higher than those for specification $\mathrm{B}$, and there- 
fore the finding that transferability improves with model specification is again demonstrated for each possible transfer. Models estimated from the 2001 dataset transfer noticeably worse to other years than the comparable models transfer to 2001.

Overall, the results demonstrate that transferability consistently improves with model specification. There is a general pattern of decreasing transferability with increasing transfer period, but the pattern is far from uniform. To summarize these results, Figure 2: Mean TI values with transfer period and model specification. presents themean TI values by transfer period and model specification.

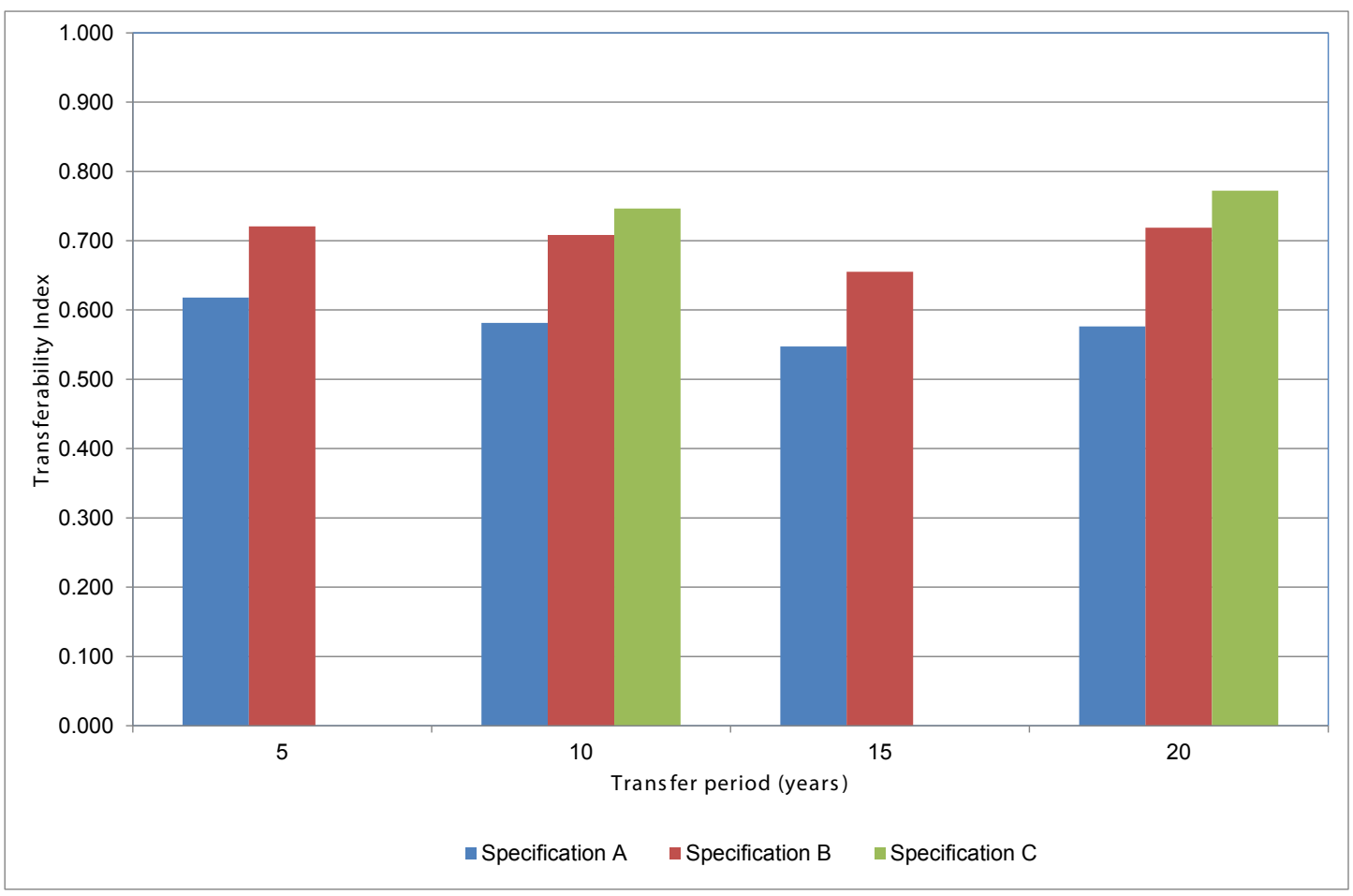

Figure 2: Mean TI values with transfer period and model specification.

Figure 2 highlights that while the transferability of the models consistently improves with model specification, there is no link between transfer period and transferability.

\subsection{Predictive tests of transferability}

In addition to the statistical tests of transferability, it is also possible to assess the ability of the transferred models to predict the changes in mode share and tour length over the transfer period. As noted in Section 5.2, there are some differences between the treatment of modes between the 2001 data and the other datasets, and therefore to prevent these differences from confusing the analysis, the 2001 data were dropped from this analysis.

Models estimated using specification $\mathrm{C}$ were used to make two sets of tests. First, 1986 models were used to predict the mode shares and tour lengths in 1996 and 2006. Second, 2006 models were used to predict the mode shares and tour lengths in 1996 and 1986.

In practice, by definition forecasts do not look back in time. However, backcasting can be a useful approach for validating model performance, and in the context of this particular analysis it provides additional data points to allow the robustness of the model estimated at a specific point in time to predict behavior at a different point in time. 
Table 10: Predictive tests of mode share, 1986 base.

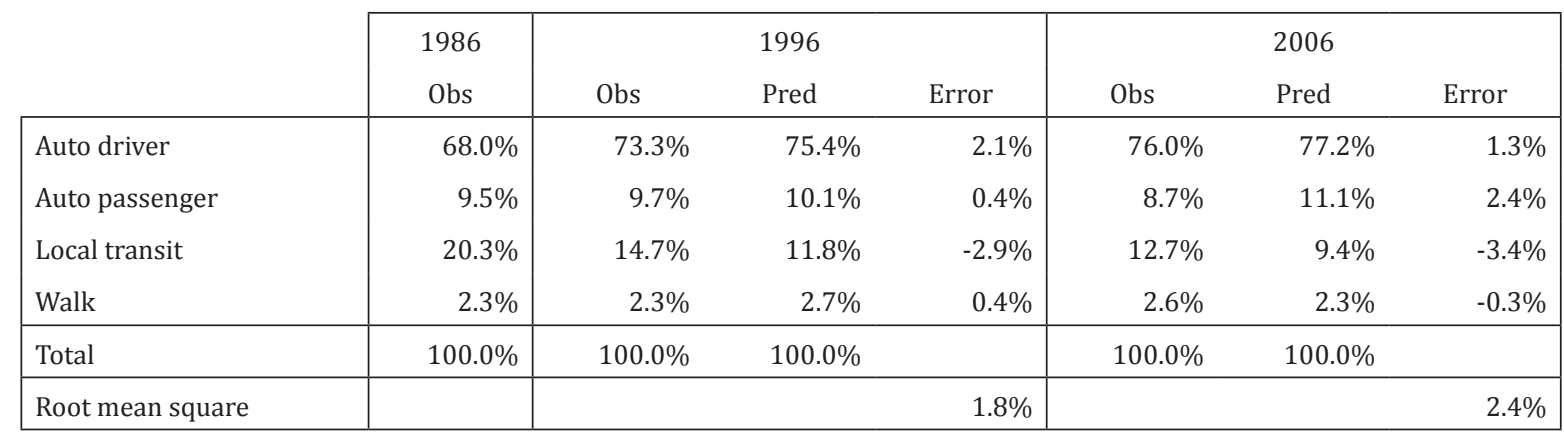

Table 11: Predictive tests of tour length $(\mathrm{km}), 1986$ base.

\begin{tabular}{|c|c|c|c|c|c|c|c|}
\hline & 1986 & \multicolumn{3}{|c|}{1996} & \multicolumn{3}{|c|}{2006} \\
\hline & Obs & Obs & Pred & Error & Obs & Pred & Error \\
\hline Auto driver & 34.0 & 40.1 & 36.3 & -3.8 & 39.5 & 38.2 & -1.3 \\
\hline Auto passenger & 28.6 & 33.0 & 29.3 & -3.7 & 29.7 & 32.2 & 2.5 \\
\hline Local transit & 23.3 & 25.9 & 23.5 & -2.5 & 25.7 & 23.0 & -2.7 \\
\hline Walk & 4.1 & 4.1 & 4.0 & 0.0 & 4.3 & 4.1 & -0.3 \\
\hline Total & 30.6 & 36.5 & 33.2 & -3.3 & 36.0 & 35.3 & -0.7 \\
\hline Root mean square & & & & 2.9 & & & 1.9 \\
\hline
\end{tabular}

The key change in mode share between 1986 and 1996 is the significant shift from transit to auto driver. It can be seen that the transferred model over-predicts this shift, and as a result the auto driver share is over-predicted in 1996 and the local transit share is under-predicted.

The transferred 1986 model also under-predicts the transit share in 2006 . There is a slight increase in the observed walk share in the 2006 data that the transferred model is unable to predict. The increase in the walk share may be due to increased awareness of the importance of regular exercise, for example, and this sort of effect is not represented in the transferred model.

Mean total tour lengths increased by $5.9 \mathrm{~km}$ between 1986 and 1996, but the transferred mode only predicts 45 percent of this increase. This under-prediction is observed for all three motorized modes. Mean total tour lengths remained more of less constant between 1996 and 2006, but the transferred model predicts a further increase between 1996 and 2006. As a result total tour lengths are predicted more closely in 2006 than in 1996.

7 A significant proportion of observed transit tours are excluded from the 2006 dataset because there is no transit path in the Emme skims for the chosen origin-destination pair. This suppresses the 2006 local transit share relative to the other years of data. 
Table 12: Predictive tests of mode share, 2006 base.

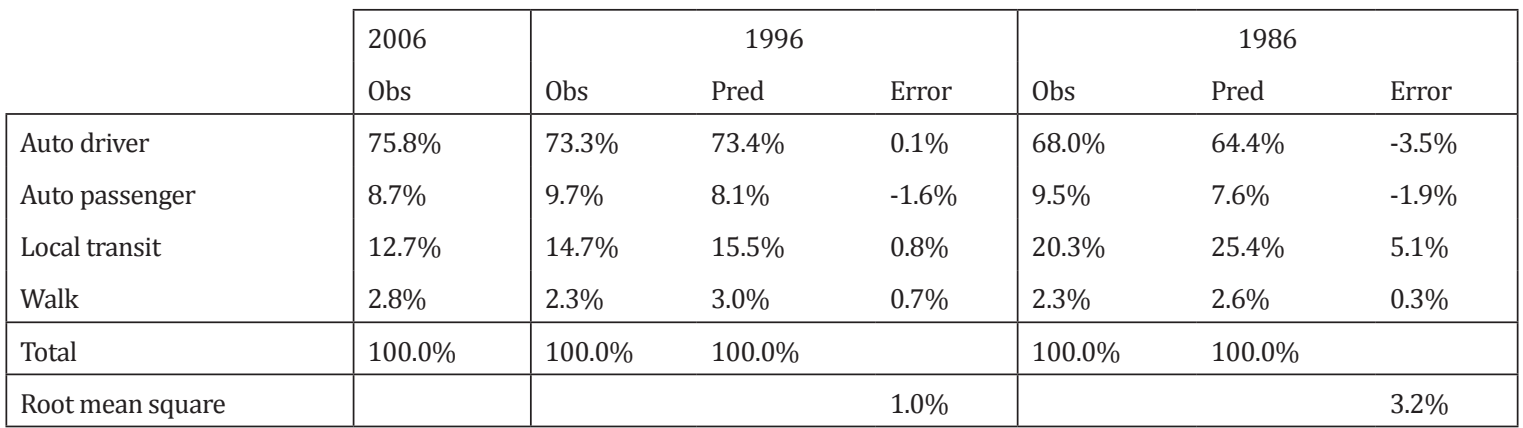

Table 13: Predictive tests of tour length (km), 2006 base.

\begin{tabular}{|l|l|lll|lll|}
\cline { 2 - 8 } \multicolumn{1}{c|}{} & \multicolumn{2}{l|}{} & \multicolumn{3}{c|}{1996} & \multicolumn{3}{c|}{1986} \\
\cline { 2 - 8 } \multicolumn{1}{c|}{} & Obs & Obs & Pred & Error & Obs & Pred & Error \\
\hline Auto driver & 39.5 & 40.1 & 38.5 & -1.6 & 34.0 & 37.6 & 3.6 \\
Auto passenger & 29.7 & 33.0 & 27.6 & -5.4 & 28.6 & 27.2 & -1.3 \\
Local transit & 25.7 & 25.9 & 27.1 & 1.2 & 23.3 & 27.2 & 3.8 \\
Walk & 4.3 & 4.1 & 4.2 & 0.2 & 4.1 & 4.3 & 0.2 \\
\hline Total & 36.0 & 36.5 & 34.8 & -1.7 & 30.6 & 33.3 & 2.6 \\
\hline Root mean square & & & & 2.9 & & & 2.7 \\
\hline
\end{tabular}

Forecasting back from 2006, the transferred 2006 model predicts the 1996 mode shares reasonably, though the change in the local transit share is again over-predicted, and the car passenger share is forecast to decrease when it actually increases.

The 1986 mode shares are predicted less well, with the decrease in auto driver share over-predicted and the increase in transit share over-predicted. This is consistent with the pattern of changes when forecasting forward from 1986-i.e., the models over-predict the extent of the switch from auto driver to transit over the 1986 to 2006 period, and in particular they over-predict the large shift over the 1986 to 1996 period.

The walk share is consistently over-predicted when forecasting back from 2006. This illustrates how the transferability of a model is reduced when the alternative specific constant is not appropriate to the transfer context.

The total tour length predictions illustrate that the transferred model predicts a $1.2 \mathrm{~km}$ reduction in tour length between 2006 and 1996, whereas observed tour lengths actually increase by $0.5 \mathrm{~km}$; between 2006 and 1986 tour lengths are observed to decrease by $5.3 \mathrm{~km}$, but the transferred model predicts only a $2.7 \mathrm{~km}$ reduction.

In summary, the transferred models over-predict the key changes in mode share over the transfer period but under-predict the key changes in tour length.

\section{$6 \quad$ Summary and next steps}

To forecast transport demands, a typical approach is to develop cross-sectional models that explain current behavior, and then use these models for forecasting. The models often incorporate segmentation, so that the impact of changes in the composition of the population over time is accounted for. However, 
application of such models relies on the assumption that the parameters that describe behavior in the base year can also be used to model behavior. Thus, the transferability of the model parameters over time is an important consideration, particularly for models applied over longer-term forecasting horizons of 20 years or more.

The focus of this research is on the temporal transferability of mode-destination choice models. The literature is generally supportive of the transferability of mode-choice models over short-term forecasting horizons of up to 5 years, but the evidence for mode-destination models is limited (only two studies) as is the evidence for models applied over longer-term forecasting horizons of 20 years or more (a single study). Therefore, further empirical evidence specific to mode-destination choice models applied over longer term forecasting horizons would be valuable.

The Toronto Transportation Tomorrow (TTS) data provides an idea dataset for testing model transferability over the longer term, as substantial well-documented surveys have been undertaken in the same area at 5-year intervals over a 20-year period. The samples of home-work trips collected in the 1986, 1996, 2001, and 2006 TTS datasets across the GTHA have been used to make the transferability tests.

To perform tests of mode-destination choice model transferability, tests were made to compare three different model specifications so that the impact of improvement in model specification on transferability could be assessed.

Analysis of changes in parameter values over time by four different groups of parameter types was undertaken. The comparisons demonstrated the level-of-service terms to be most transferable over time, and for the mean differences in parameter values to increase with transfer period. This result is insightful because it suggests that policies for which the main impact is travel time savings will be predicted more accurately than policies for which the main impact is cost changes. The socioeconomic parameters also showed relatively small changes over time. The largest differences in parameter values were observed for the model constants, and therefore, as expected, these parameters are the least transferable over time. Thus, explaining traveler's choices using behavioral parameters rather than constants would be expected to improve model transferability.

Transferred models give a better fit to the transfer dataset if cost sensitivity is reduced to take account of growth in GDP/capita over time, rather than making no adjustment to cost sensitivity, or adjusting cost sensitivity by the growth in disposable personal income over time. This approach should be used when mode-destination models are used to make forecasts of traveler behavior.

The statistical tests of model transferability clearly demonstrate that improving model specification through the addition of socioeconomic terms improves model transferability. The gain in model transferability is particularly marked when car availability parameters are added.

The models were used to predict the changes in mode share and tour length over the 20-year period. The transferred models over-predicted the shift from transit to auto driver over the 20-year period but under-predicted the observed increase in total tour lengths.

There is substantial scope for future work, but this analysis has added important empirical evidence to the under-discussed issue of model transferability. An important step will be to conduct further analysis to investigate whether advanced models such as mixed logit mode-destination choice models are more transferable over time than the nested logit models tested so far. Another important avenue for future work is to repeat the analysis on data from other areas.

\section{$7 \quad$ Acknowledgments}

The author acknowledges the financial support of a doctoral training award by the Engineering and Physical Sciences Research Council. 


\section{References}

Atherton, T. and M. Ben-Akiva. 1976. Transferability and updating of disaggregate travel demand models. Transportation Research Record: Journal of the Transportation Research Board 610: 12-18.

Badoe, D. and E. Miller. 1995. Analysis of the temporal transferability of disaggregate work trip mode choice models. Transportation Research Record: Journal of the Transportation Research Board 1493: $1-11$.

Badoe, D. and E. Miller. 1998. Modelling mode choice with data from two independent cross-sectional surveys: An investigation. Transportation Planning and Technology 21: 235-261.

Ben-Akiva, M. and T. Atherton.1977. Methodology for short-range travel demand predictions. Journal of Transport Economics and Policy 11: 224-261.

Ben-Akiva, M. 1981. Issues in transferring and updating travel-behaviour models. New Horizons in Travel-Behavior Research, edited by A. M. Stopher and P and W. Brög. Lexington Books, Lexington, 665-686.

Elmi, A., D. Badoe, and E. Miller. 1997. Transferability analysis of work-trip-distribution models. Transportation Research Record: Journal of the Transportation Research Board 1676: 169-176.

Fox, J., A. Daly, and B. Patruni. 2009. Improving the Treatment of Cost in Large Scale Models. European Transport Conference, Noordwijkerhout, The Netherlands.

Fox, J, and S. Hess. 2010. Review of evidence for temporal transferability of mode-destination models. Transportation Research Record 2175, 74-83.

Gunn, H. 2001. Spatial and temporal transferability of relationships between travel demand, trip cost and travel time. Transportation Research E37: 163-189.

Habib, K., J. Swait, and S. Salem.,2012. Investigating Structural Changes in Commuting Mode Choice Preferences with Repeated Cross-Sectional Travel Survey Data: The Contexts of Greater Toronto and Hamilton (GTHA) Area. 13 ${ }^{\text {th }}$ International Conference on Travel Behaviour Research, Toronto.

Hulchanski, D., L. Boume, M. Fair, R. Maaranen, R. Murdle, and R. Walks. 2007. The Three Cities within Toronto: Income Polarizations among Toronto's Neighbourhoods. Cities Centre, University of Toronto.

Karasmaa, N. and M. Pursula. 1997. Transferability analysis of disaggregate choice models. Transportation Research Record: Journal of the Transportation Research Board 1607: 38-44.

Koppelman, F. and C. Wilmot. 1982. Transferability analysis of disaggregate choice models. Transportation Research Record 895: 18-24.

Lerman, R. 1981. A comment on interspatial, intraspatial, and temporal transferability. New Horizons in Travel-Behaviour Research, edited by A. M. Stopher and P and W. Brög. Lexington Books, Lexington, 628-632.

McCarthy, P. 1982. Further evidence on the temporal stability of disaggregate travel demand models. Transportation Research B 16(4): 263-278.

Parody, T. 1977. Analysis of predictive qualities of disaggregate modal choice models. Transportation Research Record 637: 51-57.

Silman, L. 1981. The time stability of a modal-split model for Tel-Aviv. Environment and Planning A 13: 751-762.

Statistics Canada. 2003. Where Canadians Work and How They Get There. Minister of Industry, Ottawa.

Train, K. 1978. A validation test of a disaggregate mode choice model. Transportation Research 12: $167-174$.

Train, K. 1979. A comparison of the predictive ability of mode choice models with various levels of complexity. Transportation Research A 13: 11-16. 


\section{Appendix: Model parameters}

The following tables present the model parameter results for specifications A, B, and C defined in Table 4. To take account of differences in scale between the different years of TTS data, the 1996, 200,1 and 2006 model parameters have been re-scaled by dividing the estimated parameter values by the relevant scale parameter from Table 5 .

In each column, the parameter values are presented on the left and their associated t-ratios (the parameter value divided by the standard error) are presented on the right.

Table 14: Specification A Model Parameters.

\begin{tabular}{|c|c|c|c|c|c|c|c|c|}
\hline & \multicolumn{2}{|c|}{1986} & \multicolumn{2}{|c|}{1996} & \multicolumn{2}{|c|}{2001} & \multicolumn{2}{|c|}{2006} \\
\hline $\begin{array}{l}\text { Log-likelihood } \\
\text { Observations } \\
\text { LL per obs }\end{array}$ & & $\begin{array}{l}, 802.4 \\
50,254 \\
-6.145 \\
\end{array}$ & & $\begin{array}{r}3,565.1 \\
60,241 \\
-6.118 \\
\end{array}$ & & $\begin{array}{r}031.4 \\
5,753 \\
6.310\end{array}$ & & $\begin{array}{r}3,610.7 \\
64,959 \\
-6.444 \\
\end{array}$ \\
\hline $\begin{array}{l}\text { Cost Parameters } \\
\text { LogCost } \\
\text { Cost }\end{array}$ & $\begin{array}{r}-0.347 \\
-0.0011\end{array}$ & $\begin{array}{l}-23.1 \\
-12.8\end{array}$ & $\begin{array}{r}-0.526 \\
-0.0006\end{array}$ & $\begin{array}{r}-32.6 \\
-8.4\end{array}$ & $\begin{array}{r}0.026 \\
-0.003\end{array}$ & $\begin{array}{r}1.2 \\
-28.2\end{array}$ & $\begin{array}{r}-0.242 \\
-0.0015\end{array}$ & $\begin{array}{l}-16.1 \\
-20.8\end{array}$ \\
\hline $\begin{array}{c}\text { Level of Service } \\
\text { AutoTime } \\
\text { TranIVT } \\
\text { TranWait } \\
\text { TranWalk } \\
\text { APDist } \\
\text { WalkDist } \\
\end{array}$ & $\begin{array}{l}-0.039 \\
-0.027 \\
-0.065 \\
-0.031 \\
-0.022 \\
-0.619 \\
\end{array}$ & $\begin{array}{l}-43.9 \\
-41.4 \\
-25.8 \\
-19.3 \\
-27.5 \\
-44.5 \\
\end{array}$ & $\begin{array}{l}-0.033 \\
-0.026 \\
-0.056 \\
-0.028 \\
-0.024 \\
-0.684 \\
\end{array}$ & $\begin{array}{l}-43.4 \\
-38.8 \\
-34.4 \\
-12.2 \\
-33.1 \\
-47.8 \\
\end{array}$ & $\begin{array}{l}-0.034 \\
-0.021 \\
-0.090 \\
-0.026 \\
-0.025 \\
-0.506 \\
\end{array}$ & $\begin{array}{l}-47.2 \\
-36.0 \\
-37.5 \\
-26.1 \\
-36.7 \\
-37.6 \\
\end{array}$ & $\begin{array}{l}-0.039 \\
-0.023 \\
-0.061 \\
-0.029 \\
-0.030 \\
-0.624 \\
\end{array}$ & $\begin{array}{l}-38.3 \\
-35.5 \\
-31.4 \\
-20.8 \\
-35.0 \\
-52.3 \\
\end{array}$ \\
\hline $\begin{array}{c}\text { Destination Terms } \\
\text { CBDDest } \\
\text { CBDLT }\end{array}$ & $\begin{array}{l}0.484 \\
0.138\end{array}$ & $\begin{array}{r}14.8 \\
3.6 \\
\end{array}$ & $\begin{array}{l}0.598 \\
0.146\end{array}$ & $\begin{array}{r}17.9 \\
3.5 \\
\end{array}$ & $\begin{array}{r}-0.275 \\
1.208 \\
\end{array}$ & $\begin{array}{r}-10.0 \\
33.0 \\
\end{array}$ & $\begin{array}{r}-0.145 \\
0.945 \\
\end{array}$ & $\begin{array}{r}-5.2 \\
22.8 \\
\end{array}$ \\
\hline $\begin{array}{c}\text { Mode Constants } \\
\text { AP } \\
\text { LT } \\
\text { Wk }\end{array}$ & $\begin{array}{r}-3.722 \\
0.238 \\
-0.650\end{array}$ & $\begin{array}{r}-56.7 \\
5.5 \\
-7.6\end{array}$ & $\begin{array}{r}-4.732 \\
0.571 \\
-1.021\end{array}$ & $\begin{array}{r}-65.7 \\
9.4 \\
-11.4\end{array}$ & $\begin{array}{l}-2.744 \\
-0.101 \\
-0.506\end{array}$ & $\begin{array}{r}-28.0 \\
-2.3 \\
-37.6\end{array}$ & $\begin{array}{r}-3.459 \\
0.224 \\
0.049\end{array}$ & $\begin{array}{r}-49.3 \\
4.7 \\
0.6\end{array}$ \\
\hline $\begin{array}{c}\text { Structural Parameter } \\
\text { TR_D_M }\end{array}$ & 0.862 & 59.9 & 0.858 & 59.8 & 0.907 & 53.6 & 0.865 & 52.2 \\
\hline $\begin{array}{c}\text { Attraction Term } \\
\text { TotEmp }\end{array}$ & 1.000 & $\mathrm{n} / \mathrm{a}$ & 1.000 & $\mathrm{n} / \mathrm{a}$ & 1.000 & $\mathrm{n} / \mathrm{a}$ & 1.000 & $\mathrm{n} / \mathrm{a}$ \\
\hline
\end{tabular}


Table 15: Specification B model parameters.

\begin{tabular}{|c|c|c|c|c|c|c|c|c|}
\hline & \multicolumn{2}{|c|}{1986} & \multicolumn{2}{|c|}{1996} & \multicolumn{2}{|c|}{2001} & \multicolumn{2}{|c|}{2006} \\
\hline $\begin{array}{l}\text { Log-likelihood } \\
\text { Observations } \\
\text { LL per obs }\end{array}$ & & $\begin{array}{l}487.2 \\
254.0 \\
6.119 \\
\end{array}$ & & $\begin{array}{l}987.3 \\
241.0 \\
6.092 \\
\end{array}$ & & $\begin{array}{l}783.4 \\
753.0 \\
6.281 \\
\end{array}$ & & $\begin{array}{r}16,799.6 \\
64,959.0 \\
-6.416 \\
\end{array}$ \\
\hline $\begin{array}{c}\text { Cost Parameters } \\
\text { LogCost } \\
\text { Cost } \\
\end{array}$ & $\begin{array}{r}-0.352 \\
-0.0011 \\
\end{array}$ & $\begin{array}{l}-22.7 \\
-12.5 \\
\end{array}$ & $\begin{array}{r}-0.559 \\
-0.0006 \\
\end{array}$ & $\begin{array}{r}-33.0 \\
-7.5 \\
\end{array}$ & $\begin{array}{r}0.010 \\
-0.003 \\
\end{array}$ & $\begin{array}{r}0.4 \\
-28.2 \\
\end{array}$ & $\begin{array}{r}-0.263 \\
-0.0016 \\
\end{array}$ & $\begin{array}{r}-16.2 \\
-20.2 \\
\end{array}$ \\
\hline $\begin{array}{c}\text { Level of Service } \\
\text { AutoTime } \\
\text { TranIVT } \\
\text { TranWait } \\
\text { TranWalk } \\
\text { APDist } \\
\text { WalkDist } \\
\end{array}$ & $\begin{array}{l}-0.042 \\
-0.028 \\
-0.058 \\
-0.027 \\
-0.022 \\
-0.622\end{array}$ & $\begin{array}{l}-43.6 \\
-40.9 \\
-22.4 \\
-16.1 \\
-27.5 \\
-44.2\end{array}$ & $\begin{array}{l}-0.038 \\
-0.028 \\
-0.049 \\
-0.028 \\
-0.025 \\
-0.696 \\
\end{array}$ & $\begin{array}{l}-42.5 \\
-38.8 \\
-29.0 \\
-11.2 \\
-33.5 \\
-47.0\end{array}$ & $\begin{array}{l}-0.041 \\
-0.026 \\
-0.078 \\
-0.024 \\
-0.028 \\
-0.498\end{array}$ & $\begin{array}{l}-47.1 \\
-37.4 \\
-30.8 \\
-22.5 \\
-38.7 \\
-36.6\end{array}$ & $\begin{array}{l}-0.046 \\
-0.026 \\
-0.051 \\
-0.026 \\
-0.031 \\
-0.634 \\
\end{array}$ & $\begin{array}{l}-42.5 \\
-38.8 \\
-29.0 \\
-11.2 \\
-33.5 \\
-47.0 \\
\end{array}$ \\
\hline $\begin{array}{c}\text { Destination Terms } \\
\text { CBDDest } \\
\text { CBDLT } \\
\end{array}$ & $\begin{array}{l}0.519 \\
0.134 \\
\end{array}$ & $\begin{array}{r}15.3 \\
3.4 \\
\end{array}$ & $\begin{array}{l}0.649 \\
0.159 \\
\end{array}$ & $\begin{array}{r}18.3 \\
3.7 \\
\end{array}$ & $\begin{array}{r}-0.231 \\
1.261 \\
\end{array}$ & $\begin{array}{r}-7.4 \\
32.4 \\
\end{array}$ & $\begin{array}{r}-0.126 \\
1.015 \\
\end{array}$ & $\begin{array}{r}18.3 \\
3.7 \\
\end{array}$ \\
\hline $\begin{array}{c}\text { Mode Constants } \\
\text { AP } \\
\text { LT } \\
\text { Wk } \\
\end{array}$ & $\begin{array}{r}-4.727 \\
0.581 \\
-0.167 \\
\end{array}$ & $\begin{array}{r}-48.8 \\
12.6 \\
-1.9 \\
\end{array}$ & $\begin{array}{r}-5.913 \\
1.029 \\
-0.548 \\
\end{array}$ & $\begin{array}{r}-57.0 \\
15.8 \\
-5.7 \\
\end{array}$ & $\begin{array}{r}-3.911 \\
0.465 \\
-0.498 \\
\end{array}$ & $\begin{array}{r}-31.3 \\
9.5 \\
-36.6 \\
\end{array}$ & $\begin{array}{r}-4.480 \\
0.697 \\
0.622 \\
\end{array}$ & $\begin{array}{r}-57.0 \\
15.8 \\
-5.7 \\
\end{array}$ \\
\hline $\begin{array}{c}\text { Structural Parameter } \\
\text { TR_D_M }\end{array}$ & 0.814 & 58.4 & 0.773 & 57.8 & 0.761 & 53.5 & 0.768 & 57.8 \\
\hline $\begin{array}{c}\text { Attraction Term } \\
\text { TotEmp } \\
\end{array}$ & 1.000 & $\mathrm{n} / \mathrm{a}$ & 1.000 & $\mathrm{n} / \mathrm{a}$ & 1.000 & $\mathrm{n} / \mathrm{a}$ & 1.000 & $\mathrm{n} / \mathrm{a}$ \\
\hline $\begin{array}{l}\text { Car Availability } \\
\text { AD2pVeh } \\
\text { AP1Veh } \\
\text { AP2pVeh }\end{array}$ & $\begin{array}{l}1.212 \\
1.584 \\
2.028\end{array}$ & $\begin{array}{l}39.6 \\
21.9 \\
27.2\end{array}$ & $\begin{array}{l}1.510 \\
1.807 \\
2.283\end{array}$ & $\begin{array}{l}40.3 \\
25.5 \\
30.2\end{array}$ & $\begin{array}{l}1.703 \\
1.933 \\
2.500\end{array}$ & $\begin{array}{l}50.8 \\
27.8 \\
34.4\end{array}$ & $\begin{array}{l}1.577 \\
1.731 \\
2.232\end{array}$ & $\begin{array}{l}40.3 \\
25.5 \\
30.2\end{array}$ \\
\hline
\end{tabular}


Table 16: Specification $C$ model parameters.

\begin{tabular}{|c|c|c|c|c|c|c|}
\hline & \multicolumn{2}{|c|}{1986} & \multicolumn{2}{|c|}{1996} & \multicolumn{2}{|c|}{2006} \\
\hline $\begin{array}{l}\text { Log-likelihood } \\
\text { Observations } \\
\text { LL per obs }\end{array}$ & & $\begin{array}{r}365.0 \\
, 254.0 \\
-6.096 \\
\end{array}$ & & $\begin{array}{l}, 942.4 \\
, 241.0 \\
-6.075 \\
\end{array}$ & & $\begin{array}{r}5,706.8 \\
4,959.0 \\
-6.400 \\
\end{array}$ \\
\hline $\begin{array}{l}\text { Cost Parameters } \\
\text { LogCost } \\
\text { Cost }\end{array}$ & $\begin{array}{r}-0.358 \\
-0.0011\end{array}$ & $\begin{array}{l}-22.9 \\
-12.5\end{array}$ & $\begin{array}{r}-0.561 \\
-0.0006\end{array}$ & $\begin{array}{r}-32.8 \\
-7.7\end{array}$ & $\begin{array}{r}-0.263 \\
-0.0016\end{array}$ & $\begin{array}{l}-16.3 \\
-20.1\end{array}$ \\
\hline $\begin{array}{c}\text { Level of Service } \\
\text { AutoTime } \\
\text { TranIVT } \\
\text { TranWait } \\
\text { TranWalk } \\
\text { APDist } \\
\text { WalkDist } \\
\end{array}$ & $\begin{array}{l}-0.042 \\
-0.028 \\
-0.059 \\
-0.027 \\
-0.022 \\
-0.621 \\
\end{array}$ & $\begin{array}{l}-42.5 \\
-40.5 \\
-22.5 \\
-15.9 \\
-27.4 \\
-44.0\end{array}$ & $\begin{array}{l}-0.037 \\
-0.028 \\
-0.050 \\
-0.028 \\
-0.025 \\
-0.694 \\
\end{array}$ & $\begin{array}{l}-41.7 \\
-38.2 \\
-29.3 \\
-11.1 \\
-33.4 \\
-46.8 \\
\end{array}$ & $\begin{array}{l}-0.044 \\
-0.026 \\
-0.052 \\
-0.026 \\
-0.031 \\
-0.629 \\
\end{array}$ & $\begin{array}{l}-37.2 \\
-35.5 \\
-25.6 \\
-17.7 \\
-35.2 \\
-50.3 \\
\end{array}$ \\
\hline $\begin{array}{c}\text { Destination Terms } \\
\text { CBDDest } \\
\text { CBDLT } \\
\end{array}$ & $\begin{array}{l}0.518 \\
0.143 \\
\end{array}$ & $\begin{array}{r}15.2 \\
3.6 \\
\end{array}$ & $\begin{array}{l}0.646 \\
0.167 \\
\end{array}$ & $\begin{array}{r}18.2 \\
3.8 \\
\end{array}$ & $\begin{array}{r}-0.137 \\
1.025 \\
\end{array}$ & $\begin{array}{r}-4.5 \\
23.4 \\
\end{array}$ \\
\hline $\begin{array}{c}\text { Mode Constants } \\
\text { AP } \\
\text { LT } \\
\text { Wk } \\
\end{array}$ & $\begin{array}{r}-4.317 \\
1.023 \\
0.125 \\
\end{array}$ & $\begin{array}{r}-43.2 \\
20.3 \\
1.3 \\
\end{array}$ & $\begin{array}{r}-5.412 \\
1.539 \\
-0.136 \\
\end{array}$ & $\begin{array}{r}-50.8 \\
22.7 \\
-1.3 \\
\end{array}$ & $\begin{array}{r}-4.088 \\
1.066 \\
0.909 \\
\end{array}$ & $\begin{array}{r}-39.3 \\
20.0 \\
9.5 \\
\end{array}$ \\
\hline $\begin{array}{c}\text { Structural Parameter } \\
\text { TR_D_M } \\
\end{array}$ & 0.815 & 56.4 & 0.782 & 56.2 & 0.785 & 49.5 \\
\hline $\begin{array}{c}\text { Attraction Term } \\
\text { TotEmp } \\
\end{array}$ & 1.000 & $\mathrm{n} / \mathrm{a}$ & 1.000 & $\mathrm{n} / \mathrm{a}$ & 1.000 & $\mathrm{n} / \mathrm{a}$ \\
\hline $\begin{array}{c}\text { Car Availability } \\
\text { AD2pVeh } \\
\text { AP1Veh } \\
\text { AP2pVeh }\end{array}$ & $\begin{array}{l}1.321 \\
1.580 \\
2.019\end{array}$ & $\begin{array}{l}41.8 \\
21.8 \\
27.1\end{array}$ & $\begin{array}{l}1.608 \\
1.784 \\
2.256\end{array}$ & $\begin{array}{l}42.0 \\
25.2 \\
29.8\end{array}$ & $\begin{array}{l}1.719 \\
1.701 \\
2.197\end{array}$ & $\begin{array}{l}47.3 \\
23.4 \\
28.8\end{array}$ \\
\hline $\begin{array}{c}\text { Socio Economics } \\
\text { ADAge1617 } \\
\text { ADAge1825 } \\
\text { ADAge2630 } \\
\text { ADMale } \\
\text { WkMale }\end{array}$ & $\begin{array}{r}-2.173 \\
-0.872 \\
-0.177 \\
1.024 \\
0.275\end{array}$ & $\begin{array}{r}-6.4 \\
-25.2 \\
-5.0 \\
37.8 \\
4.1\end{array}$ & $\begin{array}{r}-3.966 \\
-1.056 \\
-0.237 \\
1.145 \\
0.153\end{array}$ & $\begin{array}{r}-4.9 \\
-22.5 \\
-6.0 \\
38.6 \\
2.1\end{array}$ & $\begin{array}{r}-3.278 \\
-1.480 \\
-0.387 \\
0.934 \\
0.161\end{array}$ & $\begin{array}{r}-5.7 \\
-32.3 \\
-8.5 \\
33.0 \\
2.5\end{array}$ \\
\hline
\end{tabular}

